\title{
A Study of Foliage Morphological Descriptions Accommodating Continuity in Previous Delimitation of Types in Tropical Plants
}

\author{
Fawibe Oluwasegun Olamide*, Ogunyale Omolara Grace, Oyelakin Abiodun Sunday, \\ Ayodele Muyiwa Segun
}

Department of Pure and Applied Botany, Federal University of Agriculture Abeokuta, Ogun State, Nigeria

Email address:

fawibeo@yahoo.com (O. O. Fawibe)

\section{To cite this article:}

Fawibe Oluwasegun Olamide, Ogunyale Omolara Grace, Oyelakin Abiodun Sunday, Ayodele Muyiwa Segun. A Study of Foliage Morphological Descriptions Accommodating Continuity in Previous Delimitation of Types in Tropical Plants. Journal of Plant Sciences. Vol. 3, No. 3, 2015, pp. 111-116. doi: 10.11648/j.jps.20150303.11

\begin{abstract}
The morphological description of some selected tropical plants in Ogun State, Nigeria was investigated. This is with a view to bridge existing more or less compartmentalized foliar descriptions which are discrete and lack the observed continuum of shape types in nature. Plants from which leaves were collected and observed for the different traits were randomly collected from some Local Government Areas of the State. The qualitative macromorphological characters observed include, leaf type, leaf shape, leaf apex, leaf base and leaf margin with varying percentage occurrence. Of the 74 distinct foliage types examined $62(84 \%)$ matched the existing foliage descriptions in literature while $12(16 \%)$ had undefined shape descriptions. It was observed that simple (79\%), ovate and lanceolate (18\%), entire (58\%), acute (26\%), acute (44\%) had the highest frequency for the leaf type, leaf shape, leaf margin, leaf apex and leaf bases respectively, while the lowest frequency was recorded to be compound (21\%), linear, oblanceolate, acicular, orbicular, sagitate, falcate, peltate, hastate, lobed (1.6\%), spinose, denticulate, crenate, parted (1.6\%), mucronulate and cirrhose $(1.6 \%)$, auriculate and hastate $(1.6 \%)$ in the leaf type, leaf shape, leaf margin, leaf apex and leaf bases respectively. Other shapes hitherto undefined include: lanceospatulate, zygomorphic-trilobe, ensiformis, lobed-pentate, lobed-starlate and ellipto-dentoid. The study revealed that there is a continuum in plant foliage macromorphological description rather than independent occurrence of plant foliage characters found in literature.
\end{abstract}

Keywords: Foliage, Qualitative, Morphology, Delimitation

\section{Introduction}

There are various descriptive terminologies in literature for plant foliage. These all present the different aspects of plant leaves in more or less compartmentalized groups which may not actually leave room for the usually observed continuity in variation of forms in nature. The usefulness of these existing descriptions cannot be overemphasized judged by their application by Taxonomists and Biosystematists.

Plant leaves are normally regarded as possessing useful characteristics for species identification $[1,7,8,4]$ However, Gwo and Wei (2013) in expressing the premise for their own study, highlighted the fact that plant identification demands extensive knowledge and such complex terminologies which even professional Botanists would require significant time in the field for mastery of the subject. One of the reasons for such challenges may not be far removed from nonaccommodation of some forms intermediate in current descriptions.

The subject of leaf traits has been reported as having a relationship with different ecological and physiological factors $[16,5,3,13,17]$. The functional significance of shape variation among leaves has been the subject of debate for many years; and there are a range of different approaches to describing leaf shape [7]. The diversity of shape suggests that there is no one ecological strategy that is dependent exclusively on leaf shape. Even within a single genus, leaf shape variation can be tremendous [8].

Leaves exhibit a remarkable diversity of shapes that range from developmental sequences within a shoot and within crown response to immediate environment; to variation 
among species within and between communities and among orders or families [8]. Many plant traits are sensitive to climate $[16,3]$. Compared with warmer sites, colder sites contained species whose leaves generally had more teeth, a larger tooth area and a higher perimeter-to-area ratio [12]. Thus the need for this current study arises, with a view to presenting if any, those forms and shapes not considered in the descriptions currently available.

\section{Materials and Methods}

Plants from which leaves were collected and observed for the different traits under study were obtained from surrounding forests of Abeokuta Metropolis, Nigeria. These are tropical plants in typical rain forest locations which include: Osiele, Camp, Obantoko, FUNAAB community in Odeda Local Government Area (711 51"N - 32612" E); Olomore, in Abeokuta North Local Government Area ( $\left.7^{\circ} 939^{\prime \prime} \mathrm{N}-3^{\circ} 2054^{\prime \prime} \mathrm{E}\right)$.

Leaf specimens severed from the plants by means of secatures, were collected in labelled polythene bags containing the plant locations, habitat growth form and position on the plants. The specimens were later prepared for preservation as described by [9]. Preserved specimens were mounted on cardboard and their pictures recorded by means of a NIKON Coolpix P90 digital model camera. Voucher specimens were deposited at the Herbarium. Qualitative characters such as leaf types, shapes, margin, base and apex were observed and scored as they occurred and recorded. The leaf characters were identified in line with existing records in various Flora and some text books.

Descriptive statistics such as frequency distribution, bar chart were used in the analysis of the data.

\section{Results}

Majority of the leaves examined $(80 \%)$ from the different plants under study were of the Simple leaf Category. The leaf shapes more pronounced in occurrence in this study were Ovate and Lanceolate (18\%); while the least occurring shapes were Linear, Oblanceolate, Acicular, Orbicular, Sagitate, Falcate, Peltate, Hastate and Lobed (1.6\%) respectively (Figure 2). The leaf margin type with the highest frequency of occurrence was Entire (58\%), followed by the Serrate margin type (28\%) Other margin types were not too conspicuous (Figure 3). The common leaf Apex forms and their percentage of occurrence include and in descending order: Acute (26\%), Apiculate (22\%), and Acuminate (19\%) Figure 4. The most pronounced leaf base type was Acute (44\%). Other fairly noticeable types ranging between 16 $18 \%$ were Rounded and Attenuate (Figure 5). Table 1 gives a holistic idea of the relative combinations of these qualitative attributes among the leaves of the different plants examined.

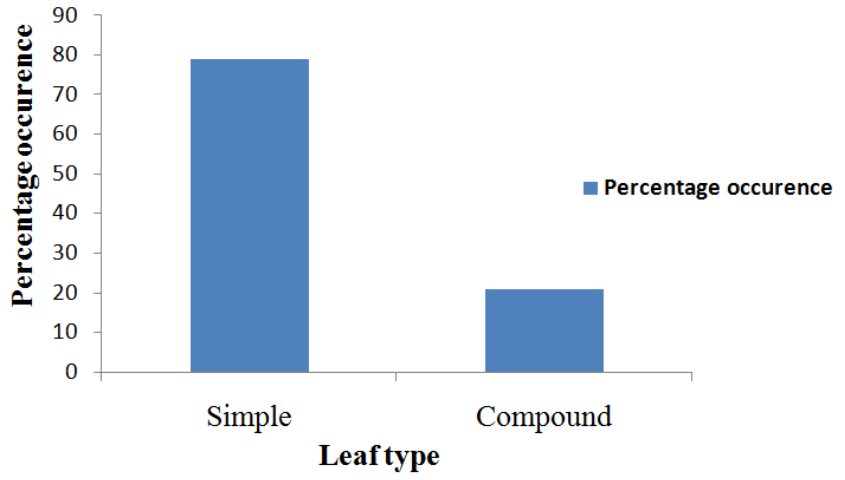

Figure 1. Frequency of the leaf types among studied specimens

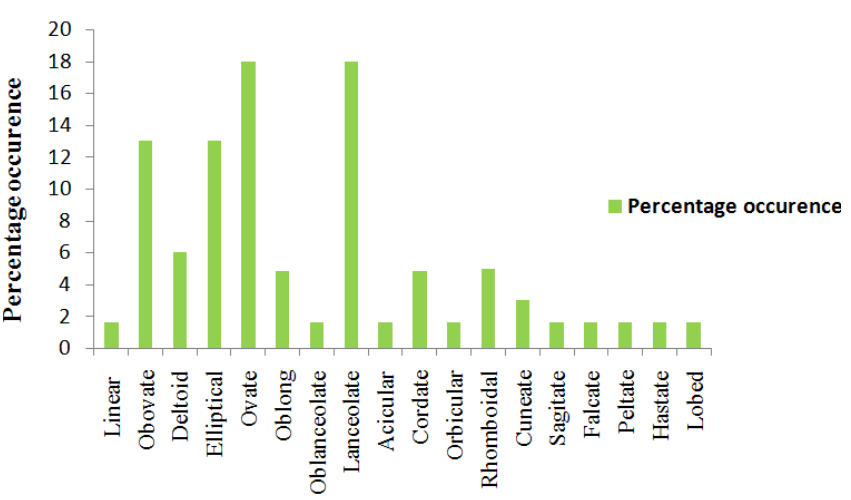

Figure 2. Frequency of leaf shape among studied specimens

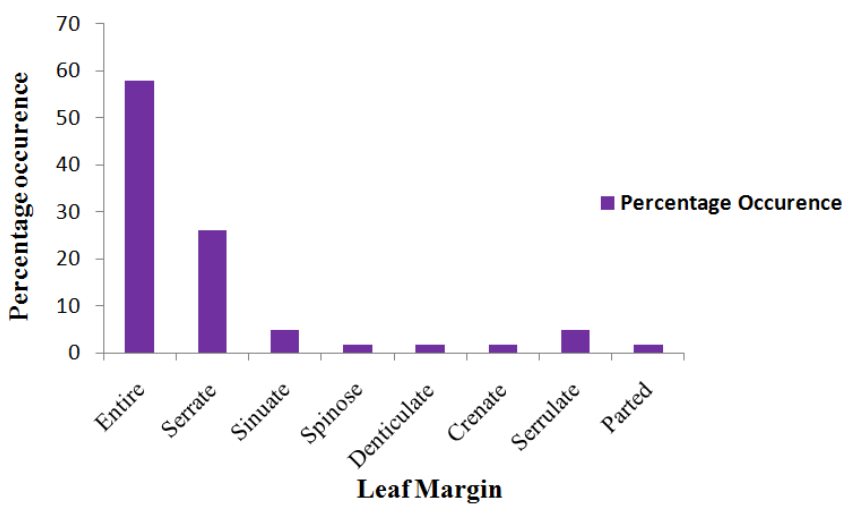

Figure 3. Frequency of the leaf margin among studied specimens

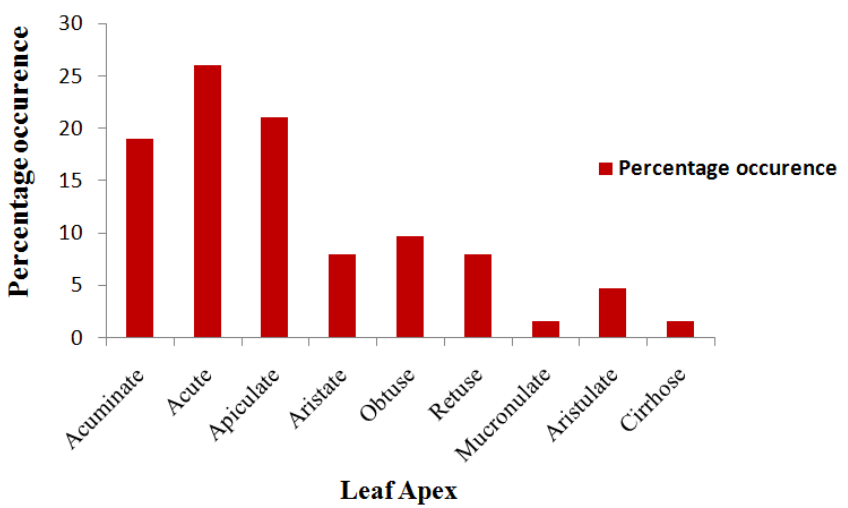

Figure 4. Frequency of the leaf apex among studied specimens 


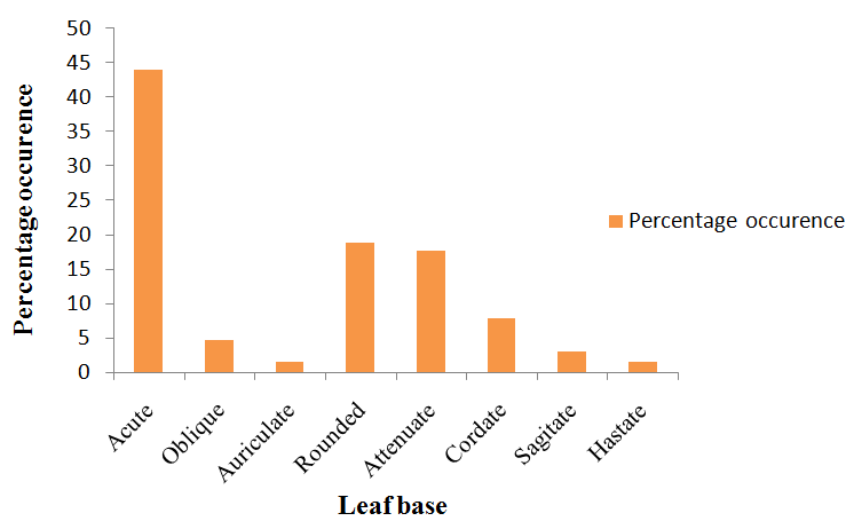

Figure 5. Frequency of the leaf base among studied specimens
Of the 74 distinct foliage types collected and examined, 62 (84\%) matched the existing foliage descriptions in literature and available Flora, while $12(16 \%)$ had undefined shape description. These had leaf qualitative traits observed among the plants examined (Figure 6) that would not readily fit into any of the existing described delimitation of types. These were separated for further comparative examination with a view to assigning an appropriate character nomenclature. Their leaf shape features and how they combine other morphological details were duly presented in Table 1. Suggestive descriptive names are as in Table 2; consisting of 9 leaf shapes and one each of leaf Apex and Margin and two of leaf Base. A glossary of the suggested descriptive terminologies are provided in Table 3.
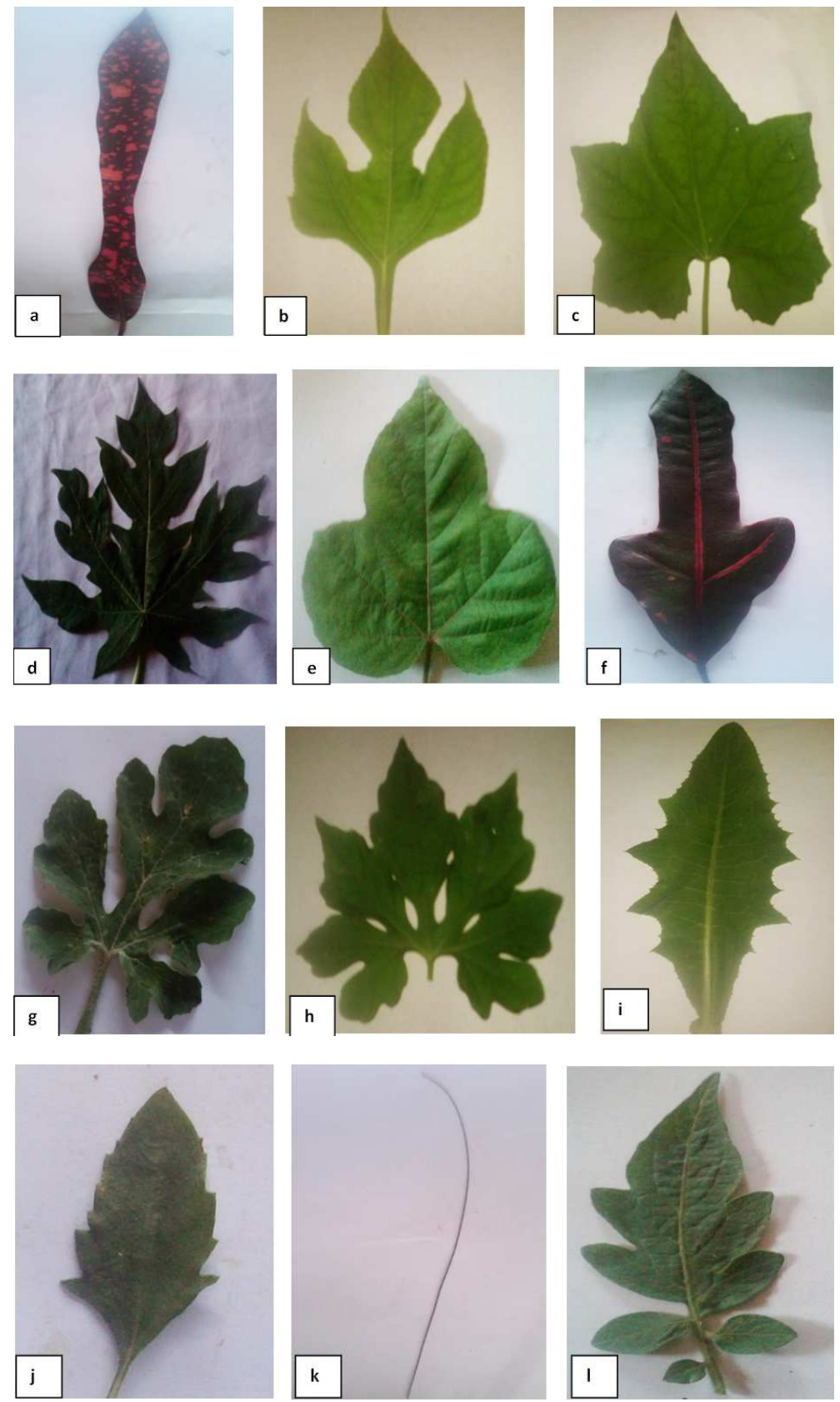

Figure 6. Pictures of leaves with undefined features and their suggested nomenclature (a) Lanceospatulate (b) Forkate (c) Starlate (d) Lobed-starlate (e) Zygomorphic trilobe (f) Ensiformate (g) Lobed -pentate (h) Octopulate (i) Ellipto-dentoid (j) Serro-dentate (k) Pinoid (l) Simpo-compound 
Table 1. Qualitative morphological characters of different leaves examined

\begin{tabular}{|c|c|c|c|c|c|}
\hline $\mathbf{S} / \mathbf{N}$ & LEAF TYPE & LEAF SHAPE & LEAF APEX & LEAF BASE & LEAF MARGIN \\
\hline 1. & Simple & Linear & Acuminate & Acute & Entire \\
\hline 2. & Simple & Obovate & Acute & Acute & Sinuate \\
\hline 3. & Simple & Deltoid & Apiculate & Acute & Serrate \\
\hline 4. & Simple & Elliptical & Aristate & Acute & Serrate \\
\hline 5. & Simple & Deltoid & Acute & Oblique & Serrate \\
\hline 6. & Simple & Ovate & Apiculate & Auriculate & Serrate \\
\hline 7. & Compound & Oblong & Obtuse & Rounded & Entire \\
\hline 8. & Compound & Ovate & Acute & Rounded & Entire \\
\hline 9. & Simple & Oblanceolate & Acute & Acute & Entire \\
\hline 10. & Simple & Lanceolate & Apiculate & Acute & Entire \\
\hline 11. & Simple & Lanceolate & Apiculate & Acute & Serrate \\
\hline 12 & Simple & Oblong & Retuse & Acute & Crenate \\
\hline 13 & Simple & Lobed & Apiculate & Acute & Serrate \\
\hline 14 & Simple & Ovate & Apiculate & Rounded & Entire \\
\hline 15 & Simple & Elliptical & Aristate & Rounded & Serrate \\
\hline 16 & Simple & Ovate & Acuminate & Attenuate & Serrate \\
\hline 17 & Simple & Obovate & Acute & Attenuate & Entire \\
\hline 18 & Compound & Lanceolate & Acuminate & Oblique & Serrate \\
\hline 19 & Simple & Acicular & Acuminate & Attenuate & Entire \\
\hline 20 & Simple & Cordate & Apiculate & Cordate & Entire \\
\hline 21 & Simple & Elliptical & Mucronulate & Rounded & Entire \\
\hline 22 & Simple & Cordate & Acute & Cordate & Serrate \\
\hline 23 & Simple & Orbicular & Acute & Cordate & Serrate \\
\hline 24 & Simple & Obovate & Retuse & Acute & Entire \\
\hline 25 & Simple & Ovate & Aristulate & Oblique & Spinose \\
\hline 26 & Simple & Rhomboidal & Aristulate & Acute & Serrate \\
\hline 27 & Compound & Ovate & Acuminate & Acute & Entire \\
\hline 28 & Compound & Ovate & Acute & Acute & Serrate \\
\hline 29 & Compound & Lanceolate & Apiculate & Acute & Entire \\
\hline 30 & Simple & Obovate & Cirrhose & Attenuate & Denticulate \\
\hline 31 & Compound & Lanceolate & Aristate & Acute & Entire \\
\hline 32 & Simple & Elliptic & Acute & Attenuate & Entire \\
\hline 33 & Simple & Cordate & Apiculate & Cordate & Serrate \\
\hline 34 & Simple & Cuneate & Retuse & Acute & Entire \\
\hline 35 & Simple & Obovate & Obtuse & Acute & Entire \\
\hline 36 & Simple & Elliptical & Apiculate & Attenuate & Sinuate \\
\hline 37 & Simple & Rhomboidal & Acute & Acute & Serrate \\
\hline 38 & Simple & Obovate & Obtuse & Acute & Entire \\
\hline 39 & Simple & Ovate & Apiculate & Attenuate & Serrulate \\
\hline 40 & Compound & Lanceolate & Acuminate & Acute & Entire \\
\hline 41 & Simple & Elliptical & Retuse & Acute & Entire \\
\hline 42 & Compound & Rhomboidal & Acuminate & Acute & Parted \\
\hline 43 & Simple & Ovate & Acute & Cordate & Sinuate \\
\hline 44 & Simple & Lanceolate & Acuminate & Attenuate & Entire \\
\hline 45 & Simple & Ovate & Acuminate & Acute & Entire \\
\hline 46 & Simple & Lanceolate & Acuminate & Rounded & Entire \\
\hline 47 & Simple & Ovate & Aristate & Rounded & Serrulate \\
\hline 48 & Simple & Deltoid & Acute & Rounded & Entire \\
\hline 49 & Simple & Deltoid & Acute & Rounded & Serrulate \\
\hline 50 & Simple & Sagitate & Apiculate & Sagitate & Entire \\
\hline 51 & Simple & Lanceolate & Aristate & Acute & Entire \\
\hline 52 & Compound & Elliptical & Retuse & Rounded & Entire \\
\hline 53 & Simple & Obovate & Obtuse & Attenuate & Entire \\
\hline 54 & Compound & Falcate & Acuminate & Attenuate & Entire \\
\hline 55 & Simple & Cuneate & Obtuse & Attenuate & Entire \\
\hline 56 & Simple & Obovate & Apiculate & Acute & Entire \\
\hline 57 & Simple & Lanceolate & Aristulate & Rounded & Entire \\
\hline 58 & Compound & Oblong & Obtuse & Rounded & Entire \\
\hline 59 & Simple & Elliptical & Acute & Acute & Entire \\
\hline 60 & Compound & Lanceolate & Acuminate & Acute & Sinuate \\
\hline 61 & Simple & Peltate & Acute & Sagitate & Entire \\
\hline 62 & Simple & Hastate & Acute & Hastate & Entire \\
\hline
\end{tabular}


Table 2. Morphological features of undefined leaf characters (in bold print)

\begin{tabular}{lllll}
\hline FIGURE 6 & LEAF SHAPE & LEAF APEX & LEAF BASE & LEAF MARGIN \\
\hline $\mathrm{a}$ & Lancespathulate & Acute & Rounded & Entire \\
$\mathrm{b}$ & Forkate & Acuminate & Attenuate & Serrulate \\
$\mathrm{c}$ & Starlate & Acuminate & Auriculate & Serrulate \\
$\mathrm{d}$ & Lobed-starlate & Acuminate & Sagitate & Lobate \\
$\mathrm{e}$ & Zygomorphictrilobe & Acute & Acute & Entire \\
$\mathrm{f}$ & Ensiformate & Acute & Acute & Entire \\
$\mathrm{g}$ & Lobed-pentate & Obtuse & Auriculate & Sobate \\
$\mathrm{h}$ & Octopulate & Acute & Auriculate & Double -dentate \\
$\mathrm{i}$ & Ellipto-dentoid & Obtuse & Acute & Serrodentate \\
$\mathrm{j}$ & Ovate & Acute & Acute & Entire \\
$\mathrm{k}$ & Filiform & Pinoid & Pinoid & Sinuate \\
\hline
\end{tabular}

Table 3. Glossary of upgraded foliar descriptions

\begin{tabular}{ll}
\hline Terminology & Description \\
\hline Lanceospatulate & A lance-shaped leaf with a broad apex which tappers at the middle to give a broad base \\
Forkate & Fork - shaped leaf \\
Starlate & Star - shaped leaf \\
Lobed-starlate & A lobed star - shaped leaf \\
Zygomorphic-trilobe & A simple leaf with two sides lobed at equal angle from the same axis. \\
Ensiformate & Sword- shaped leaf \\
Lobed-pentate & A five - lobed shaped leaf. \\
Octopulate & Octopus- shaped leaf \\
Ellipto-dentoid & An Elliptic-shaped leaf with dentate margin \\
Serrodentate & Leaf with serrate margin towards the apex and dentate margin towards the base \\
Pinoid apex and base & A sharp pointed apex and base \\
Simpo-compound & A leaf that looks simple towards the apex but splits towards the base into leaflets \\
\hline
\end{tabular}

\section{Discussion}

Plant leaves manifest a remarkable diversity of shapes, margins, apices and bases that range from developmental sequences within and between communities.

Morphologically, the leaves in the area studied were predominantly simple with acute apex, entire margin and acute base. These results were similar to those of species from other tropical rainforest vegetation $[6,2]$. This similarity might have resulted from comparable species composition and/or from convergent development as a response to similar environmental condition [10].

The less occurrence of compound leaves compared to simple leaves in this region could be attributed to the ecological factors of this region. This was supported by [14] who reported that compound leaves seem to be more common in warmer and arid or semi-arid environments and in light demanding species. Their shape, arrangement and construction are thought to offer advantages in capturing light while reducing water loss and maintaining lower leaf lamina temperatures.

Ovate leaves with acute or acuminate apex and entire margins prominent in these areas can be associated with the high pluviosity of the area [6]. It has been suggested that this leaf morphology worked as drainage triggerers [11] which probably retards the growth of epiphylls and reduces loss of soluble nutrients by leaching [15].

Shape, margin, apex and base variation among leaves have been the subject of debate for many years. The undefined leaf qualitative traits among the plants observed showed that there is a continuum in plant foliage morphology rather than independent occurrence of foliar description has appeared in text. Proposed leaf margin such as Serro-dentate, may fill the gap between the serrate and dentate margin while the Lanceospathulate may bridge the gap between the Lanceolate and Spathulate leaf shape. Understudied foliage also showed some "Shapes" attributes which better described them than generalized acronym. Proposed leaf shape such as Zygomorphic-trilobed, Ensiformate and Starlate showed better description than "lobed" as appeared in literature.

The study revealed that there is a continuum in plant foliage macromorphological description rather than independent occurrence of plant foliage characters found in literature.

\section{References}

[1] E. M. Armstrong. "Leaf Types and Shapes" URL : en.wikipedia.org/wiki/leaf type and shapes. Retrieved 12-052014

[2] F. Bongers and J. Popma, "Leaf characteristics of the tropical rainforest Flora of Los Tuxtlas", Mexico Botanical Gazette, vol 151, pp. 354-365, 1990 
[3] S. W. Breckle, Walter's vegetation of the earth: the ecological systems of the geo-biosphere", 4th edn. Berlin, Germany: Springer-Verlag, 2002

[4] C. Gwo and C. Wei, "Plant identification through images: using feature extraction of keypoints on leaf contours" Applications in Plant Sciences, vol 1, pp. 1200005, 2013

[5] B. Kirchoff, "Character description in phylogenetic analysis: insights from Agnes Arber's concept of the plant", Annals of Botany vol 88, pp $1203-1214,2001$

[6] T. O. Maria, C. A. Luiz and B. N. Raquel, "Leaf morphology of 89 tree species from a lowland tropical rain forest (Atlantic forest) in South Brazil", Brazilian Archives of Biology and Technology vol 47 (6), pp. 21-24. 2004

[7] A. B. Nicotra. Leaf size and shape. Prometheus wiki.http://prometheuswiki.publish.csiro.au./tikiindex.php?pa ge $=$ Leaf + size + and + shape (Verified 2 July 2014), 2010

[8] A. B. Nicotra, A. Leigh, C. K. Boyce, C. S. Jones, K. J. Niklas, D. L. Royer and H. Tsukaya, "The evolution and functional significance of leaf shape in the angiosperm", Funct Plant Biol vol 38, pp.535-552, 2011

[9] O. Olorode. Taxonomy of West African Flowering Plants. The Book Project. Nigeria Obafemi Awolowo University, Ile-Ife, 2011, pp: $14-17$
[10] M. Pyykko, "Morphology and Anatomy of leaves from some woody plants in a humid tropical forest of Venezuelan Guayana", Acta. Bot. Fennica, vol 112 pp. 1-41, 1979

[11] P. W. Richards. The tropical rainforest: an ecological study ( $2^{\text {nd }}$ ed.), U.K. Cambridge University Press, 1996, pp. 44-56

[12] D. L. Royer, P. Wilf, D. A. Janesko, E. A. Kowalski and D. L. Dilcher, "Correlations of climate and plant ecology to leaf size and shape: potential proxies for the fossil record" American Journal of Botany vol 92, pp. 1141-1151, 2005

[13] M. Tsiantis, A. Hay, "Morphological innovations in plant leaves - origin" Nature review: Genetics vol 4, pp. 169-180, 2003

[14] L. Warman, T. Moles, W. Edwards. "Not so simple after all: searching for ecological advantages of compound leaves". Nordic Society Oikos vol 000, pp. 001-09, 2010

[15] T. C. Whitemore. An introduction to tropical rain forests. Oxford. Oxford University Press, 1998, pp. 30-34

[16] F. I. Woodward, Climate and plant distribution. Cambridge, UK. Cambridge University Press, 1987, pp 35-52

[17] P. Wright, B. Groom and B. Lamon "Functional Plant Biology". 2004 pp. $551-558$ 